\title{
Complicaciones respiratorias en el posoperatorio de cirugía cardíaca en adultos
}

\author{
Dres. Sergio Cáceres, Olivier Bertaux, Ignacio Porras
}

\section{Resumen}

Todos los pacientes que cursan un posoperatorio de cirugía cardíaca desarrollan alteraciones respiratorias. Por esta razón, es muy importante la implementación de todas las medidas tendientes a minimizar el impacto de estas. El verdadero desafío consiste en la detección precoz de dichas complicaciones y el desarrollo de estrategias terapéuticas tempranas con el objetivo de minimizar su impacto. En el presente trabajo, se analizan las principales complicaciones respiratorias en el escenario del posoperatorio de cirugía cardíaca y las acciones terapéuticas correspondientes.

$\begin{array}{ll}\text { Palabras clave: } & \text { CIRUGÍA CARDÍACA } \\ & \text { POSOPERATORIO }\end{array}$

COMPLICACIONES RESPIRATORIAS

\section{Respiratory complications in the postoperative period of cardiac surgery in adults \\ Summary}

All patients who undergo cardiac surgery develop respiratory disorders in the postoperative period. It is very important to implement all measures to minimize the impact of these alterations. The real challenge consists in the early detection of complications and the development of early therapeutic strategies in order to minimize their impact. In the present study, the main respiratory complications in the postoperative setting of cardiac surgery, and the corresponding therapeutic actions, are analyzed.

Key words: $\quad$ CARDIAC SURGERY

POSTOPERATIVE

RESPIRATORY COMPLICATIONS

\section{Complicações respiratórias no pós-operatório de cirurgia cardíaca em adultos}

\section{Resumo}

Todos os pacientes submetidos à cirurgia cardíaca desenvolvem distúrbios respiratórios no pós-operatório. É muito importante implementar todas as medidas para minimizar o impacto dessas alterações. $O$ verdadeiro desafio consiste na detecção precoce das complicações e no desenvolvimento de estratégias terapêuticas precoces de forma a minimizar o seu impacto. No presente trabalho, são analisadas as principais complicações respiratórias no pós-operatório de cirurgia cardíaca e as respectivas ações terapêuticas.

$\begin{array}{ll}\text { Palavras chave: } & \text { CIRURGIA CARDÍACA } \\ & \text { PÓS-OPERATÓRIO } \\ & \text { COMPLICAÇÕES RESPIRATÓRIAS }\end{array}$

Centro Cardiológico Americano, Sanatorio Americano. Montevideo, Uruguay.

Correspondencia: Dr. Sergio Cáceres. Correo electrónico: sercace@gmail.com

Los autores declaran no tener conflicto de intereses.

Recibido Oct 5, 2020; aceptado Oct 27, 2020 


\section{Introducción}

La mayoría de los pacientes que reciben una cirugía cardíaca desarrollan alteraciones respiratorias posoperatorias, desde leves a severas. Múltiples factores perioperatorios influyen sobre la función pulmonar y la mecánica torácica. El síndrome de respuesta inflamatoria vinculado al insulto quirúrgico explica especialmente las alteraciones.

El aumento en la edad, la presencia de enfermedades respiratorias preexistentes y la prevalencia de tabaquismo agregan sustrato para las complicaciones.

\section{Cambios posoperatorios de la función pulmonar}

Están generalmente vinculados a alteraciones ventilación/perfusión (V/Q) y del shunt intrapulmonar. El compromiso respiratorio persiste varios meses; los valores del volumen espiratorio forzado en el primer segundo $\left(\mathrm{VEF}_{1}\right)$, del flujo espiratorio forzado en el $50 \%$ de la capacidad vital forzada $\left(\mathrm{FEF}_{50}\right)$ y la ventilación máxima voluntaria en un minuto (VMM), mantienen valores $25 \%$ inferiores a los cuatro meses de la intervención. Los factores intervinientes $^{(1)}$ se agrupan en la tabla 1.

\section{Complicaciones}

Es importante tomar iniciativas tempranas de prevención. Siguiendo el protocolo ERAS Cardiac ${ }^{(2)}$, se formulan las siguientes recomendaciones para disminuir la incidencia de complicaciones respiratorias posoperatorias (tabla 2 ).

Para estandarizar la terminología utilizamos las Guías para Definiciones de Complicaciones Pulmonares Perioperatorias publicadas en 2015 por la European Joint Task Force ${ }^{(3,4)}$.

\section{a. Falla o insuficiencia respiratoria}

Valor de $\mathrm{PaO}_{2}<60 \mathrm{mmHg}$ ventilando al aire, $\mathrm{PaO}_{2} / \mathrm{FiO}_{2}<300 \mathrm{mmHg}$ o $\mathrm{SpO}_{2}<90 \%$ y requerimiento de oxígeno para estabilización, dejando de lado situaciones crónicas. Todos los pacientes operados tienen un cierto grado de insuficiencia respiratoria que en la mayoría de los casos es autolimitada a pocas horas en el posoperatorio. Algunos mantendrán disfunción respiratoria más prolongada de causa multifactorial y requerirán cierto soporte ventilatorio, generalmente no invasivo.

Usualmente presentan factores de riesgo previos como edad avanzada, enfermedades pulmonares, mal acondicionamiento físico y respiratorio, tabaquismo, fragilidad, alteraciones nutricionales, anemia, etcétera.
Tabla 1. Causas y condiciones predisponentes a los cambios respiratorios posoperatorios en cirugía cardíaca.

Vinculadas al paciente

- Edad avanzada.

- Tabaquismo.

- Agravación de enfermedades preexistentes (EPOC bronquitis crónica, malformaciones torácicas).

- Obesidad con patrón restrictivo respiratorio.

Vinculadas a la anestesia

- Anestésicos generales, BNM y BZD o sedantes reducen el estímulo respiratorio central y la función de músculos respiratorios.

- Anestésicos inhalatorios inhiben la vasoconstricción hipóxica pulmonar.

- Disminución de la CRF $20 \%$.

- Elevación diafragmática con alteración V/Q y aumento de DA-a $\mathrm{O}_{2}$.

- Disminución del surfactante con aumento de atelectasias.

Vinculadas a la CEC

- Pulmón de bomba.

- Hemodilución, hipervolemia e hiposmosis pueden ocasionar edema pulmonar cardiogénico.

Vinculada a la cirugía

- Extracción de arteria mamaria interna (AMI) disminuye PEF, VEF1, CVF, CRF y VRE.

- Mayor frecuencia de derrame pleural y atelectasias.

- La esternotomía mediana y los drenajes de tórax agregan rigidez torácica y dolor con taquipnea.

- Disfunción o parálisis diafragmática por lesión y/o desvascularización del nervio frénico durante la extracción de la AMI, o por la irrigación con agua helada del espacio pericárdico.

- Edema pulmonar por disfunción ventricular izquierda poscardiotomía con aumento de PAP y eventual compromiso VD.

- Edema pulmonar intersticial no cardiogénico secundario a la respuesta inflamatoria sistémica, con aumento de la permeabilidad endotelial y del volumen extravascular pulmonar.

- Transfusiones introducen mediadores inflamatorios que aumentan la RVP, PAP y reducen la oxigenación.

EPOC: enfermedad pulmonar obstructiva crónica; BNM: bloqueantes neuromusculares; BZD: benzodiazepinas; CRF: capacidad residual funcional; DA-a O2: diferencia alveolo-arterial de oxígeno; CEC: circulación extracorpórea; PAP: presión de arteria pulmonar; VD: ventrículo derecho; RVP: resistencias vasculares pulmonares. $\mathrm{V} / \mathrm{Q}$ : ventilación/perfusión; VEF1: volumen espiratorio forzado en el primer segundo; CVF: capacidad vital forzada; VRE: volumen de reserva espiratoria. 
Tabla 2. Medidas preventivas de complicaciones respiratorias.

\begin{tabular}{lll}
\hline \multicolumn{1}{c}{ Preoperatorias } & \multicolumn{1}{c}{ Intraoperatorias } & \multicolumn{1}{c}{ Posoperatorias } \\
\hline Acondicionamiento físico & Ventilación pulmonar protectora & Adecuada analgesia \\
Corregir anemia & & Movilización precoz \\
Adecuada nutrición & Evitar excesiva expansión del volumen & Incentivar fisioterapia respiratoria. \\
Incentivar ejercicios respiratorios & Evitar altas dosis de anestésicos o BZD & Extubación precoz oportuna \\
& & Prevención del delirium \\
& & Nutrición oral precoz \\
\hline BZD: benzodiazepinas. & & \\
\hline
\end{tabular}

El bypass cardiopulmonar (BPCP) -especialmente si es prolongado-, la transfusión de sangre intraoperatoria y el aporte excesivo de soluciones contribuyen en forma importante.

Durante el posoperatorio pueden aparecer e interactuar cuadros con diversa intensidad que inician y mantienen la insuficiencia respiratoria, como broncoespasmo, traqueobronquitis, derrames pleurales, atelectasias, dolor pleurítico, restricción torácica por la esternotomía, depresión y angustia, entre otros.

Las estrategias fundamentales para disminuir las complicaciones incluyen: manejo adecuado del $\mathrm{BPCP}$, uso de presión positiva al final de la espiración (PEEP) y ventilación protectora durante la cirugía ${ }^{(5)}$.

El tratamiento estará dirigido al diagnóstico y corrección del factor desencadenante junto a una intensa fisioterapia respiratoria, movilización pasiva-activa y soporte ventilatorio mediante oxígeno de alto flujo (OAF), o ventilación no invasiva (VNI) con diferentes niveles de presión soporte (PS) o PEEP, o ambos.

El uso de transfusiones sanguíneas y hemoderivados, cuya asociación con complicaciones pulmonares ha sido documentada ampliamente, puede desencadenar un cuadro definido como TRALI (Transfusion Lung Injury) con hipoxia, infiltrados pulmonares dentro de las siguientes seis horas de la transfusión, taquipnea, cianosis, disnea y fiebre. Su prevalencia en cirugía cardíaca se estima en $3 \%$, con una mortalidad entre 5\%-25\%. Presenta una fisiopatología compleja en la que se cumple una hipótesis de evento doble: en primer término se produce una acumulación de neutrófilos en la circulación pulmonar; a continuación, ocurre un aumento de la permeabilidad capilar pulmonar provocada por anticuerpos contenidos en la transfusión. Las transfusiones son un factor independientemente asociado a complicaciones pulmonares, aun sin desarrollo de TRALI. Las transfusiones de glóbulos rojos tienen significativamente más riesgo ajustado de compli- caciones en comparación con quienes no las reciben: síndrome de distrés respiratorio agudo (SDRA) $(4,8 \%$ vs. $1,5 \%)$, insuficiencia respiratoria ( $2,2 \%$ vs. $0,39 \%)$, ventilación mecánica prolongada $(9,9 \%$ vs. $7,5 \%)$ y reintubación ( $5,6 \%$ vs. $1,3 \%)$.

El manejo de la anemia posoperatoria con una estrategia restrictiva de reposición hematimétrica adoptando un umbral de 7,5 g/dl ha disminuido su frecuencia y la de los eventos respiratorios asociados.

\section{b. Síndrome de distrés respiratorio agudo}

Es la principal causa de insuficiencia respiratoria grave posoperatoria, con una mortalidad de hasta $80 \%$. Aumenta la estadía hospitalaria y la morbilidad a largo plazo. No hay pacientes exentos de riesgo de desarrollarlo. Se asocia al BPCP, transfusión de hemoderivados, cambios bruscos en el volumen intravascular e injuria pulmonar vinculada a la ventilación mecánica. La incidencia es variable: según la metodología se estima entre 0,4\%-20\%.

$\mathrm{Su}$ frecuencia es mayor en síndromes aórticos agudos (SAA) graves (50\%), cirugía valvular $(8,1 \%)$, donde la cirugía tricuspídea actúa como predictor independiente $(\mathrm{OR}=5,2)$ y en la cirugía de emergencia.

Para su diagnóstico y estratificación de severidad se utiliza la definición de Berlín del año $2012^{(6)}$ (tabla 3).

Kor y colaboradores ${ }^{(7)}$ desarrollaron el SCORE SLIP-2 para identificar pacientes en riesgo de desarrollar SDRA basado en nueve predictores independientes que incluyen: sepsis, cirugía aórtica, cirugía cardíaca de alto riesgo, según EuroSCORE o STS SCORE, cirugía de emergencia, cirrosis, admisión desde otro centro, polipnea (20-29 rpm o $>30 \mathrm{rpm}$ ), $\mathrm{FiO}_{2}$ mayor a $35 \%$ y $\mathrm{SpO}_{2}<95 \%$.

Desde el punto de vista fisiopatológico, durante el BPCP la circulación de la sangre sobre superficies y condiciones anormales inicia una respuesta inflamatoria sistémica que explica parte del comienzo del SDRA. La activación del complemento con liberación de C3a y C5a tiene un rol central, originando 


\begin{tabular}{|c|c|c|}
\hline Tiempo & \multicolumn{2}{|c|}{$\begin{array}{l}\text { Hipoxemia aparecida dentro de la primera semana de un insulto clínico o nueva } \\
\text { peoría de síntomas respiratorios. }\end{array}$} \\
\hline Radiografía tórax & \multicolumn{2}{|c|}{$\begin{array}{l}\text { Opacidades bilaterales en la radiografía de tórax no vinculadas a derrame, colapso } \\
\text { alveolar, nódulos. }\end{array}$} \\
\hline Origen del edema & \multicolumn{2}{|c|}{$\begin{array}{l}\text { No vinculado a falla cardíaca o sobrecarga de volumen. A veces es necesaria la } \\
\text { evaluación ecocardiográfica. }\end{array}$} \\
\hline \multirow[t]{3}{*}{ Oxigenación y estratificación } & Leve & Índice $\mathrm{PaO}_{2} / \mathrm{FiO}_{2}$ entre 200 y $300 \mathrm{mmHg}$ con PEEP o CPAP $\geq 5$ cm H $\mathrm{H}_{2} \mathrm{O}$. \\
\hline & Moderado & Índice $\mathrm{PaO}_{2} / \mathrm{FiO}_{2}$ entre 200 y $100 \mathrm{mmHg}$ con $\mathrm{PEEP} \geq 5 \mathrm{~cm} \mathrm{H}_{2} \mathrm{O}$. \\
\hline & Severo & Índice $\mathrm{PaO}_{2} / \mathrm{FiO}_{2} \leq 100 \mathrm{mmHg}$ con PEEP $\geq 5 \mathrm{~cm} \mathrm{H}_{2} \mathrm{O}$. \\
\hline
\end{tabular}

acumulación de neutrófilos activados en la circulación pulmonar y liberación de contenido lisosomal, produciendo injuria pulmonar difusa. Este proceso puede amplificarse en los síndromes de bajo gasto, la hipoperfusión esplácnica y la isquemia intestinal con traslocación de endotoxinas bacterianas. La protamina activa el complemento, contribuyendo al cuadro.

El SDRA puede presentarse en cirugías sin BPCP, por efecto del estrés quirúrgico solamente.

Es importante prevenir su aparición mediante la identificación de pacientes con mayor riesgo de desarrollarlo y su manejo adecuado; entre las medidas a tomar se propone:

1. Disminuir la duración del BPCP, que activa vías inflamatorias y oxidativas con producción de isquemia pulmonar e injuria por reperfusión. Sin embargo, no hubo diferencias en la incidencia de SDRA entre técnicas con o sin BPCP, salvo en el subgrupo de pacientes con enfermedades pulmonares preexistentes, añosos o de alto riesgo para SDRA.

2. Evitar la hiperoxia con oxígeno al $100 \%$, que lleva al colapso alveolar y la generación de radicales libres, exacerbando la isquemia-reperfusión.

3. Utilización de circuitos revestidos de heparina. Las técnicas de disminución leucocitaria, cell savers y la ultrafiltración intraoperatoria no han demostrado beneficios en los ensayos clínicos.

\section{Tratamiento}

El manejo restrictivo de fluidos mejora la función pulmonar, disminuye las horas de ventilación mecánica y la estadía en terapia intensiva, sin aumentar otras fallas orgánicas.

El uso de estrategias de ventilación mecánica dirigidas a la protección pulmonar que evitan el daño secundario (VILI) juegan un rol fundamental en la prevención y en el tratamiento, deben ser usadas tanto en el intraoperatorio ${ }^{(8)}$ como durante la estadía en terapia intensiva.

Altos volúmenes corrientes $\left(\mathrm{V}_{\mathrm{T}}\right)$ se asocian a liberación de mediadores inflamatorios que llevan al daño pulmonar ${ }^{(9)}$.

La ventilación mecánica (VM) protectora pulmonar consiste en ${ }^{(10)}$

- $\quad \mathrm{V}_{\mathrm{T}} 6 \mathrm{ml} / \mathrm{kg}$ de peso corporal estimado.

- Presiones de insuflación $(\Delta \mathrm{P})<16 \mathrm{~cm} \mathrm{H}_{2} \mathrm{O}$.

- Presión meseta $<30 \mathrm{~cm} \mathrm{H}_{2} \mathrm{O}$.

- PEEP altas en torno a $15 \mathrm{~cm} \mathrm{H}_{2} \mathrm{O}$.

El pulmón en el SDRA severo se presenta con áreas heterogéneas de aireación y colapso. El uso de PEEP intenta evitar el colapso y reclutar unidades alveolares. Para esto también se utilizan las maniobras de reclutamiento alveolar (MRA) que producen apertura de áreas atelectásicas a través de altas presiones transpulmonares controladas y de breve duración. Los estudios presentan resultados controversiales en cuanto a mejora de la oxigenación y disminución de la mortalidad. Cui y colaboradores, en un reciente metaanálisis ${ }^{(11)}$, analizaron estudios relevantes hasta mayo de 2018 comparando MRA con un grupo control. Se incluyeron 3.025 pacientes en diez estudios. No hubo diferencias significativas en la mortalidad hospitalaria a 28 días, como tampoco en la estadía en terapia intensiva ni en el requerimiento de oxígeno, incluso realizando análisis de subgrupos. Hubo menor estadía hospitalaria global y mejoría del índice $\mathrm{PaO}_{2} / \mathrm{FiO}_{2}$ al tercer día. Los resultados deben interpretarse cautelosamente por su heterogeneidad.

El uso precoz de bloqueantes neuromusculares (BNM) dentro de las 48 horas de inicio del SDRA severo mejoró la sobrevida a 90 días y disminuyó el tiempo de ventilación mecánica sin incrementar la debilidad muscular (HR 0,68; IC95\%: 0,48-0,98; $\mathrm{p}=0,04)^{(12)}$.

La ventilación mecánica en posición prono demostró beneficio en el estudio PROSEVA(13), con 
disminución de la mortalidad a 28 y 90 días ( $16 \%$ vs. $33 \%$; $p<0,001$ y $29 \%$ vs. $41 \%$; $<<0,001$, respectivamente), los días de ventilación y el tiempo a la extubación. El mayor beneficio en sobrevida ocurrió en el grupo con $\mathrm{PaO}_{2} / \mathrm{FiO}_{2}<150 \mathrm{mmHg}$.

Indudablemente, el posoperatorio de cirugía cardíaca presenta características particulares por la esternotomía, la pericardiotomía, puentes arteriales o venosos u otros procedimientos. No obstante, desde hace años se vienen publicando series de casos con buenos resultados en SDRA severo ventilados en decúbito prono ${ }^{(14,15)}$. El beneficio se observa incluso en pacientes obesos (índice de masa corporal [IMC] $>30 \mathrm{~kg} / \mathrm{m}^{2}$ ), pero a expensas de mayores lesiones por presión(16).

El protocolo para colocar al paciente en decúbito prono consiste en ${ }^{(17)}$ :

- Definir SDRA según criterios de Berlín.

- Definir la severidad en paciente sedado utilizando la herramienta Richmond Agitated Sedation Score (RASS-4/-5), curarizado y adaptado al ventilador.

- Indicación temprana dentro de las primeras 24-36 horas del inicio, cuando el beneficio es mayor.

- Estrategia de ventilación pulmonar protectora ( $\mathrm{V}_{\mathrm{T}} 6 \mathrm{ml} / \mathrm{kg}$ peso corporal), $\mathrm{PEEP} \geq 5 \mathrm{~cm} \mathrm{H}_{2} \mathrm{O}$, presión meseta $<30 \mathrm{~cm} \mathrm{H}_{2} \mathrm{O}$, presión de insuflación <16 cm $\mathrm{H}_{2} \mathrm{O}$ y $\mathrm{FiO}_{2}$ para una $\mathrm{SpO}_{2}$ de $88 \%-92 \%$.

- Requiere un equipo de cuatro personas. Proteger áreas propensas a las lesiones de decúbito como pelvis, rodillas, hombros y cara.

- Luego de realizar la maniobra de pronación, reevaluar el nivel de PEEP.

- Se debe mantener de 16-20 horas diarias como mínimo, pero pueden haber días durante los cuales se debe alternar posiciones de los brazos (posición de nadador).

- Se suspende cuando se observa beneficio por $\mathrm{PaO}_{2} / \mathrm{FiO}_{2}>150 \mathrm{mmHg}$ al menos 4 horas en posición supina luego del prono con PEEP $\leq 10 \mathrm{~cm}$ $\mathrm{H}_{2} 0$ y $\mathrm{FiO}_{2} \leq 60 \%$, o perjuicio como deterioro de la oxigenación por disminución del $\mathrm{PaO}_{2} / \mathrm{FiO}_{2}>20 \%$ en decúbito prono comparado con supino.

- Estar atentos a eventos adversos que puedan ocurrir:

- Extubación accidental.

- Desaturación mantenida $<85 \%$ o $\mathrm{PaO}_{2}<55$ mmHg con $\mathrm{FiO}_{2} 100 \%$ sostenida más de 5 minutos.

- Paro cardiorrespiratorio (PCR) o bradicardia severa ( $\leq 30 \mathrm{pm}$ más de un minuto).

- Hipotensión - presión arterial sistólica < 60 mmHg durante más de cinco minutos.
El uso de corticoides sigue en debate. Villar y colaboradores ${ }^{(18)}$, del Dexamethasone ARDS Group, en un estudio multicéntrico español, randomizaron pacientes con SDRA moderado a severo definidos como índice $\mathrm{PaO}_{2} / \mathrm{FiO}_{2} \leq 200 \mathrm{mmHg}, \mathrm{PEEP} \geq 10 \mathrm{~cm}$ $\mathrm{H}_{2} \mathrm{O}$ y $\mathrm{FiO}_{2}>0,5$ más de 24 horas luego del inicio del SDRA. El grupo tratamiento recibió dexametasona $20 \mathrm{mg}$ intravenosa (IV) en una dosis diaria del primer al quinto día y luego $10 \mathrm{mg}$ IV en una dosis del sexto al décimo día. Ambos grupos recibieron estrategias de ventilación mecánica pulmonar protectora. En el grupo dexametasona el resultado primario de días de ventilación mecánica fue favorable con menos tiempo en ventilación; la diferencia entre grupos fue de 4,8 días (IC95\%: 2,57-7,03; $\mathrm{p}=0,0001$ ). El resultado secundario de mortalidad por cualquier causa a 60 días fue también favorable $21 \%$ vs. $36 \%$; diferencia entre grupos $-15,3 \%$ $(-25,9 \%$ a $-4,9 \% ; p=0,0047)$. Hubo mayor número de hiperglicemias (76 vs. $70 \%$ ), iguales cifras de sepsis y neumonía ( $24 \%$ vs. $25 \%$ ).

\section{c. Barotrauma pulmonar}

Es la presencia de aire extraalveolar debido a ruptura alveolar. El exceso lleva a neumotórax, neumomediastino y enfisema subcutáneo. Es una complicación de la VM invasiva y en menor grado con la modalidad no invasiva. Se correlaciona con incremento de la morbimortalidad. Los pacientes bajo VM invierten las presiones intratorácicas con una inspiración positiva que es la causante del barotrauma. Los pacientes con mayor riego de barotrauma son los portadores de enfermedad pulmonar obstructiva crónica (EPOC), asma, enfermedades pulmonares intersticiales, neumonía asociada a la ventilación (NAV) y SDRA.

El diagnóstico se basa en la sospecha clínica, pesquisa frecuente y atención a elementos indirectos, porque en el paciente crítico sedado -y a veces curarizado- los síntomas no se presentan. En el neumomediastino o neumopericardio se observan líneas radiolúcidas que contornean el corazón o el mediastino, o ambos. En el neumotórax existe un aumento de diámetro del hemitórax involucrado, ausencia de murmullo alveolovesicular (MAV), hipersonoridad, hipoxia e hipotensión secundaria a shock obstructivo en caso de neumotórax a tensión.

El ventilador aporta información útil en la evaluación del barotrauma pulmonar por la aparición de disincronía paciente-ventilador ${ }^{(19)}$, brusca elevación de la presión pico y plateau por encima de $30 \mathrm{~cm}$ $\mathrm{H}_{2} \mathrm{O}$, o brusca disminución del $\mathrm{V}_{\mathrm{T}}$ entregado. La medida preventiva más eficaz es mantener presiones pico y meseta debajo de $30 \mathrm{~cm} \mathrm{H}_{2} \mathrm{O}$ y nunca encima de $35 \mathrm{~cm} \mathrm{H}_{2} \mathrm{O}$. 
Tabla 4. Causas de disfunción diafragmática.

Hipotermia local con hielo: aumenta la incidencia ocho veces, siendo algo menos frecuente con suero salino frío y se debe a desmielinización del nervio frénico.

Disección de la arteria mamaria izquierda con tracción de vasos nutrientes nerviosos.

Canulación yugular.

FEVI severamente disminuida en el preoperatorio.

Diabetes mellitus descompensada.

Paresia diafragmática sin lesión frénica por inhibición refleja de la actividad muscular por estímulo directo excesivo mantenido de los nervios frénico y vago.

Reducción de la contractilidad muscular por fatiga o lesión directa por retractores de campo.

Inhibición dolorosa al movilizar el diafragma durante la ventilación.

FEVI: fracción de eyección del ventrículo izquierdo.

El neumotórax no hipertensivo de pequeño volumen, generalmente apical, el enfisema subcutáneo, el neumopericardio y el neumomediastino se resuelven espontáneamente tomando una conducta de observación cuidadosa. El neumotórax hipertensivo requiere la evacuación de emergencia sin esperar la radiografía. A veces aparece un neumomediastino anterior, sospechado por la presencia de drenaje de aire permanente por los tubos y enfisema subcutáneo, y que resulta inaparente en la radiografía convencional, requiriendo una tomografía de tórax para su confirmación. Se resolverá en conjunto con cirujano cardíaco o torácico si se requiere intervenir por sospecha de fistula aérea, mediante abordaje terapéutico por videotoracoscopía.

\section{d. Disfunción diafragmática}

Es la reducción de la función contráctil del diafragma. La incidencia en cirugía cardíaca se estima entre $26 \%-85 \%$ y es una importante causa de VM prolongada y dificultad en la desvinculación del ventilador. Su principal causa es la lesión del nervio frénico en su trayecto intrapericárdico.

Se presenta en obstrucciones agudas o crónicas de las vías respiratorias, situaciones que generen auto-PEEP, en cirugías torácicas y en la polineuromiopatía del enfermo crítico. Los factores predisponentes se enumeran en la tabla 4.

El grado de disfunción es variable. Usualmente es asintomática cuando es unilateral. La paresia raramente es bilateral $(0,5 \%-2,1 \%)$ pero en este caso produce una disfunción grave con prolongación de la VM y asocia mortalidad $>25 \%$.
Se sospecha ante dificultad en la desvinculación mayor a seis días luego de excluir otras causas como sepsis, neumonía, falla cardíaca, disfunción neurológica. Clínicamente presenta disnea, participación de músculos accesorios y movimiento paradójico abdominal. El patrón funcional es restrictivo, con reducción de la capacidad vital forzada (CVF), la capacidad residual funcional, (CRF), el VEF1 y el VT. Disminuye la compliance estática (C.est). La radiografía muestra elevación del hemidiafragma afectado y atelectasias basales subyacentes. La ecografía pleural ha sustituido a la radioscopía para el diagnóstico y seguimiento.

Moury y colaboradores ${ }^{(20)}$ midieron ecográficamente en 100 cirugías cardíacas la fracción de engrosamiento del hemidiafragma (FED) como criterio subrogante de trabajo respiratorio. Una FED $<20 \%$ fue definida como baja. Encontraron en 75 pacientes una baja FED durante la prueba de ventilación espontánea (PVE). No hubo cambios vinculados al tipo de cirugía o el método de enfriamiento. El grosor diafragmático y la FED se correlacionaron con la duración de la cirugía. Hubo relación entre el grosor diafragmático, la evolución de la FED y la estadía en terapia intensiva.

Cavayas y colaboradores ${ }^{(21)}$ determinaron que una FED baja predice complicaciones pulmonares posoperatorias independientemente de indicadores de fragilidad, sarcopenia y función pulmonar.

\section{e. Neumonía asociada a la ventilación mecánica}

La NAV se define como aquella que ocurre luego de la intubación orotraqueal y en las 48 horas posteriores al inicio de la asistencia ventilatoria mecánica $(\mathrm{AVM})^{(22,23)}$.

Se desarrolla en 10\%-40\% de los pacientes sometidos a AVM, existiendo grandes variaciones entre países y tipos de unidades de cuidados intensivos (UCI), con una mortalidad atribuible estimada en $13 \%$, mayor en pacientes quirúrgicos ${ }^{(24,25)}$.

Los factores de riesgo que contribuyen al desarrollo de neumonía en pacientes sometidos a cirugía cardíaca se describen en la tabla $5^{(22)}$.

Los mecanismos patogénicos de colonización por microorganismos se resumen en la tabla 6. Dado que no hay un gold standard para el diagnóstico de $\mathrm{NAV}^{(26)}$, debemos sospecharla en pacientes que presentan algunos de los elementos enumerados en la tabla $7^{(22,27)}$.

Las guías priorizan para el diagnóstico y el seguimiento el score CPIS (Modified Clinical Pulmonary Infection Score) con una sensibilidad de $74 \%$ y especificidad de $66 \%{ }^{(22,26)}$. Un score CPIS $\geq 6$ se correlaciona con una probable NAV (tabla 8). 
Tabla 5. Factores de riesgo para neumonía asociada a la ventilación mecánica.

Edad avanzada.

EPOC.

Insuficiencia cardíaca previa

Alteraciones en la mecánica pulmonar secundarias a la esternotomía.

Edema pulmonar multifactorial.

Extubación luego de 24-48 horas de la cirugía.

BPCP prolongado por su efecto sobre los mediadores inflamatorios sistémicos y potencial de lesión pulmonar.

Uso de hemoderivados durante el BPCP.

EPOC:enfermedad pulmonar obstructiva crónica; BPCP: bypass cardiopulmonar.

Tabla 7. Criterios de sospecha de neumonía asociada a la ventilación mecánica.

Temperatura axilar $>38,3^{\circ} \mathrm{C}$

Nuevo infiltrado pulmonar o progresión de infiltrado previo

GB $\geq 12.000$ o $<4.000$

Secreciones purulentas

Deterioro del intercambio gaseoso, aumento de la PEEP $>3$, o aumento $>20 \% \mathrm{FiO}_{2}$.

GB: glóbulos blancos; PEEP: positive end expiratory pressure.

Las Guías Británicas recomiendan considerar, además, el aumento en el requerimiento de oxígeno objetivado a través de la PEEP o índice $\mathrm{PaO}_{2} / \mathrm{FiO}_{2}$. Este dato se considera muy relevante en la nueva definición epidemiológica de los Centros de Control y Prevención de Enfermedades de Estados Unidos (CDC) y la vigilancia de las NAV en una unidad. Un reciente metaanálisis de los criterios diagnósticos de NAV, hasta setiembre de 2019, con un total de 25 estudios $(\mathrm{n}=1.639)$ comprueba la pobre sensibilidad y especificidad de los criterios diagnósticos (tabla 9).

No se recomienda el uso de biomarcadores como proteína $\mathrm{C}$ reactiva o procalcitonina para el diagnóstico, pero este último puede tener utilidad en el seguimiento $^{(28)}$.

Existe controversia en el diagnóstico microbiológico de NAV. En una revisión Cochrane de 2014, la evidencia de los ensayos incluidos indica que no hay ventajas clínicas con el uso de cultivos cuantitativos sobre los cualitativos, ni con el uso de enfoques de diagnóstico invasivos sobre los no invasivos ${ }^{(29)}$. Los métodos cuantitativos realizan un recuento bacteriano que puede diferenciar un proceso infeccioso de la colonización por la mayor cantidad de
Tabla 6. Mecanismos patogénicos de colonización de la vía aérea.

Inhalación a través de las vías respiratorias o sonda endotraqueal.

Aspiración de secreciones colonizadas procedentes de la orofaringe.

Vía hematógena a partir de focos de infección distantes o de la flora intestinal a través de translocación bacteriana.

Contigüidad desde infecciones adyacentes a los pulmones.

Tabla 8. Score CPIS.

\begin{tabular}{|c|c|c|}
\hline Criterio & Valor & Puntaje \\
\hline \multirow[t]{3}{*}{ Temperatura ${ }^{\circ} \mathrm{C}$} & $36,5-38,4$ & 0 \\
\hline & $38,5-38,9$ & 1 \\
\hline & $\geq 39-<36$ & 2 \\
\hline \multirow{2}{*}{$\begin{array}{l}\text { Glóbulos } \\
\text { blancos }\end{array}$} & $>4.000-<11.000$ & 0 \\
\hline & $<4.000->11.000$ & 1 \\
\hline \multirow{4}{*}{$\begin{array}{l}\text { Secreciones } \\
\text { traqueales }\end{array}$} & Pocas & 0 \\
\hline & Moderadas & 1 \\
\hline & Abundantes & 2 \\
\hline & Purulentas & +1 \\
\hline \multirow{2}{*}{$\begin{array}{l}\text { Oxigenación } \\
\mathrm{PaO}_{2} / \mathrm{FiO}_{2}\end{array}$} & $\begin{array}{l}>240 \text { o presencia de } \\
\text { SDRA }\end{array}$ & 0 \\
\hline & $\begin{array}{l}<240 \text { o ausencia de } \\
\text { SDRA }\end{array}$ & 1 \\
\hline \multirow[t]{3}{*}{ Radiología } & Sin infiltrado & 0 \\
\hline & $\begin{array}{l}\text { Infiltrado difuso o } \\
\text { parcheado }\end{array}$ & 1 \\
\hline & Infiltrado localizado & 2 \\
\hline
\end{tabular}

unidad formadora de colonias (UFC). Los métodos cualitativos se centran en la presencia o ausencia de patógenos. Una de sus limitantes es que la muestra puede estar contaminada por flora que coloniza la vía aérea superior, siendo menos específicos.

Los métodos diagnósticos invasivos tienen costos elevados, requieren condiciones adecuadas de realización y personal calificado. Se desaconsejan en SDRA severo. Los métodos no invasivos pueden sobrestimar la presencia de bacterias en el examen inicial de las muestras, conduciendo a un uso excesivo de antibióticos.

Las guías europeas priorizan las muestras invasivas y cuantitativas, habiendo discrepancias sobre 
Tabla 9. Sensibilidad y especificidad de los criterios diagnósticos de neumonía aguda asociada a la ventilación mecánica.

\begin{tabular}{lcc|}
\hline & Sensibilidad & Especificidad \\
\hline Fiebre & $66 \%$ & $54 \%$ \\
Secreciones traqueales & $77 \%$ & $39 \%$ \\
Radiografía de tórax & $89 \%$ & $26 \%$ \\
Aspirado traqueal & $76 \%$ & $68 \%$ \\
LBA & $72 \%$ & $80 \%$ \\
CPIS & $74 \%$ & $66 \%$ \\
\hline $\begin{array}{l}\text { LBA: lavado bronquioalveolar; CPIS: Modified Clinical Pul- } \\
\text { monary Infection Score. }\end{array}$ & \\
\hline
\end{tabular}

rendimiento entre muestras distales (lavado bronquio-alveolar [LBA]/cepillo protegido) y proximales (aspirado traqueal).

Por el contrario, las guías americanas IDSA/ ATS de 2016 establecen preferencia diagnóstica por la muestra no invasiva con cultivos semicuantitativos, basado en estudios que no revelan diferencias en mortalidad o estadía hospitalaria con ninguno de los enfoques.

Se consideran recuento significativo ${ }^{(30)}$

- $10^{3} \mathrm{UFC} / \mathrm{ml}$, con cepillo protegido,

- $10^{4} \mathrm{UFC} / \mathrm{ml}$ en LBA,

- $10^{6} \mathrm{UFC} / \mathrm{ml}$ en aspirado traqueal.

Si bien se mantiene la definición de neumonía temprana y tardía según el tiempo de estadía en la unidad u hospital (punto de corte: quinto día) utilizada para guiar el tratamiento antibiótico empírico, el advenimiento de microorganismos multirresistentes (MOR), ha hecho cambiar la estrategia, dado que varios estudios muestran tasa de MOR en neumonía temprana entre $10 \%-50 \%{ }^{(22)}$.

$\mathrm{Al}$ plantear un tratamiento antibiótico (ATB) debemos recordar:

- $\mathrm{Su}$ inicio debe ser precoz, ya que disminuye la mortalidad.

- Dirigido a gérmenes probables.

- Conocer la ecología bacteriana local.

- Conocer prevalencia de MOR, se considera alta si es $>25 \%$.

- Investigar factores de riesgo para MOR (uso de ATB 90 días previos, internación más de cinco días, shock séptico, SDRA, terapia de remplazo renal).

- Siempre realizar relevo microbiológico previo.

- Realizar dosis carga de los antimicrobianos con dosis plenas en las primeras 24 horas del tratamiento, independientemente de la función renal. Optimizar su uso según su farmacocinética y farmacodinamia (PK/PD).
- Dirigir o modificar el tratamiento según germen obtenido, severidad del cuadro y evolución clínica.

- Evitar doble cobertura antibiótica para pseudomonas, salvo en pacientes con shock ${ }^{(31)}$.

- Reevaluar tratamiento si los cultivos fueran negativos, o si luego de 72 horas de instaurada la terapéutica cursa con mala evolución.

- Definir cobertura antibiótica empírica entre espectro reducido o amplio con el fin de prevenir la aparición de resistencias y efectos secundarios.

La selección del tratamiento ATB en NAV temprana y tardía se realizará valorando factores de riesgo del paciente, severidad de la enfermedad, frecuencia y tipo de MOR en la unidad.

El plan ATB empírico inicial, en NAV temprana, sin factores de riesgo y baja prevalencia de MOR, estará dirigido a gérmenes como neumococo, Haemophilus influenzae, Staphylococcus aureus meticilino sensible (SAMS), y se sugiere monoterapia con ampicilina-sulbactam, cefalosporinas de segunda y tercera generación (sin cobertura específica para Pseudomonas aeruginosa), levofloxacina o moxifloxacina.

En NAV tardía, los agentes causales tienen alto riesgo de resistencia a ATB como Pseudomonas aeruginosa, Acinetobacter baumannii, Staphylococcus aureus resistente a la meticilina (SAMAR) y otros bacilos gramnegativos, dependiendo del microorganismo predominante en cada hospital y terapia intensiva.

En pacientes con alto riesgo para MOR, alta prevalencia en la unidad y sin shock séptico, se sugiere monoterapia, cubriendo más del $90 \%$ de las bacterias Gram negativas de la unidad. Si tiene factores de riesgo para SAMAR o prevalencia en la unidad $\geq 25 \%$, realizar cobertura con vancomicina.

Con factores de riesgo para MOR, prevalencia mayor a $25 \%$ y shock séptico, realizar terapia ATB combinada, con cobertura para Pseudomonas aeruginosa y valorar también factores de riesgo para SAMAR y su cobertura ATB(22,32) (figura 1).

Las guías americanas y europeas sugieren una duración de tratamiento de siete días con buena evolución, ya que es tan efectivo como duraciones más prolongadas y reduce la aparición de MOR.

En aquellos pacientes donde el tratamiento inicial fue inadecuado, se debe tratar por más de siete días. Se extiende 10 a 14 días en: bacteriemias, paciente inmunodeprimido, fibrosis quística, empiemas, neumonías cavitadas o necrotizantes.

No recomienda el uso de ATB nebulizados como tratamiento adyuvante. Dos ensayos controlados aleatorios recientes no pudieron demostrar su superioridad (amikacina sola o combinada con fosfo- 


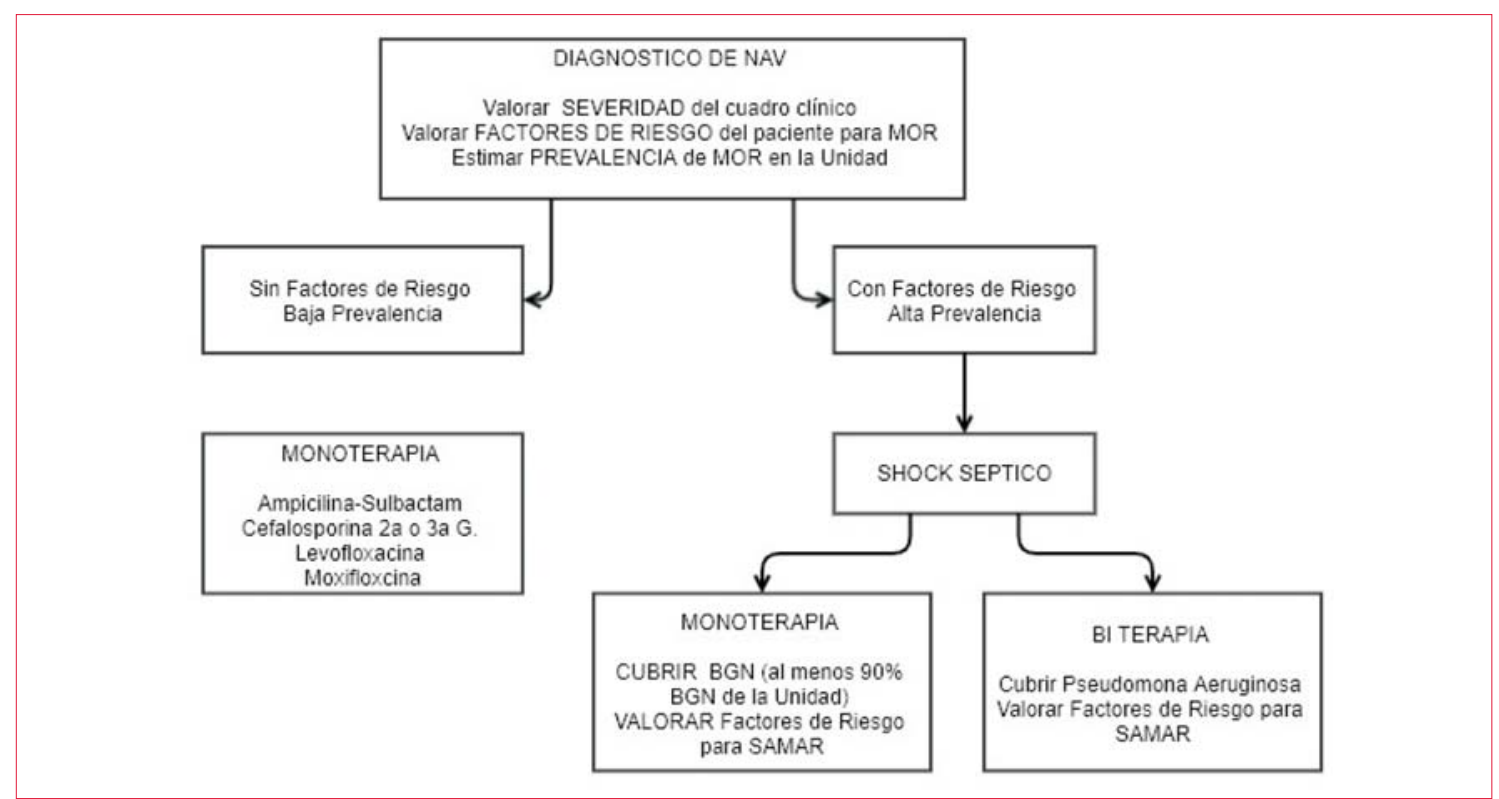

Figura 1. Algoritmo de terapéutica antibiótica en NAV. NAV: neumonía asociada a la ventilación; MOR: microorganismos multirresistentes; G: generación; BGN: bacilos gramnegativos; SAMAR: Staphylococcus aureus resistente a la meticilina

micina) sobre placebo en pacientes con NAV sin MOR. En cambio, en pacientes con NAV a MOR (solo sensibles a una o dos familias de ATB) en tres metaanálisis, el uso de colistina nebulizada combinada con colistina IV produjo mejores resultados que la colistina IV, sola ${ }^{(33)}$.

\section{f. Derrame pleural}

Es la ocupación por líquido de la cavidad pleural. El examen puede revelar disnea, taquipnea, tos seca, dolor pleurítico, uso de músculos accesorios respiratorios, cianosis y un síndrome en menos torácico con abolición de murmullo alveolovesicular, vibraciones y matidez a la percusión. La radiografía de tórax de pie muestra ocupación del ángulo costofrénico que en forma de curva puede extenderse hacia el ápex por la cara axilar y pérdida de la silueta diafragmática; en posición supina se observa desplazamiento de estructuras adyacentes u opacidad difusa en un hemitórax con vasculatura preservada.

Son más frecuentes cuando se aborda la cavidad pleural, presentándose hasta en un 60\%. Suelen ser serosos, serohemáticos o hemáticos.

Varios estudios demostraron que el sangrado posoperatorio, derrame pleural, atelectasia y la estadía hospitalaria fueron mayores en el grupo con apertura de pleura ${ }^{(34)}$.

Los pequeños derrames se reabsorben. Derrames mayores con compromiso de la dinámica respiratoria con respiración restrictiva y/o desaturación se sugiere drenarlos para acortar la evolución y mejorar el cuadro.
Tabla 10. Criterios diagnósticos del síndrome pospericardiotomía.

Fiebre sin causa alternativa.

Dolor torácico pleurítico.

Roce pleural o pericárdico.

Derrame pleural.

Derrame pericárdico.

Leucocitosis $>12.000$.

Los derrames posoperatorios no complicados son los más frecuentes y carecen de signos de inflamación sistémica.

Los derrames tabicados requieren una especial evaluación imagenológica para determinar la decisión de drenaje simple o mediante videotoracoscopía por cirujano de tórax. Los casos recidivantes pueden deberse al síndrome pos-pericardiotomía (SPP), complicación posoperatoria con incidencia entre $10 \%-40 \%$ por criterios diagnósticos inhomogéneos, ocurriendo días o semanas luego de la cirugía. Existe inflamación con proteína $\mathrm{C}$ reactiva elevada e hiperleucocitosis. El daño celular pericárdico o del mesotelio pleural combinado con sangre actúa como disparador. Hay correlación entre la severidad y elevación de anticuerpos antimiosina.

Para el diagnóstico se necesitan la presencia de dos o más de los criterios mencionados en la tabla 10.

La conducta sugerida se basa en el uso preventivo de antiinflamatorios no esteroideos (AINEs), co- 


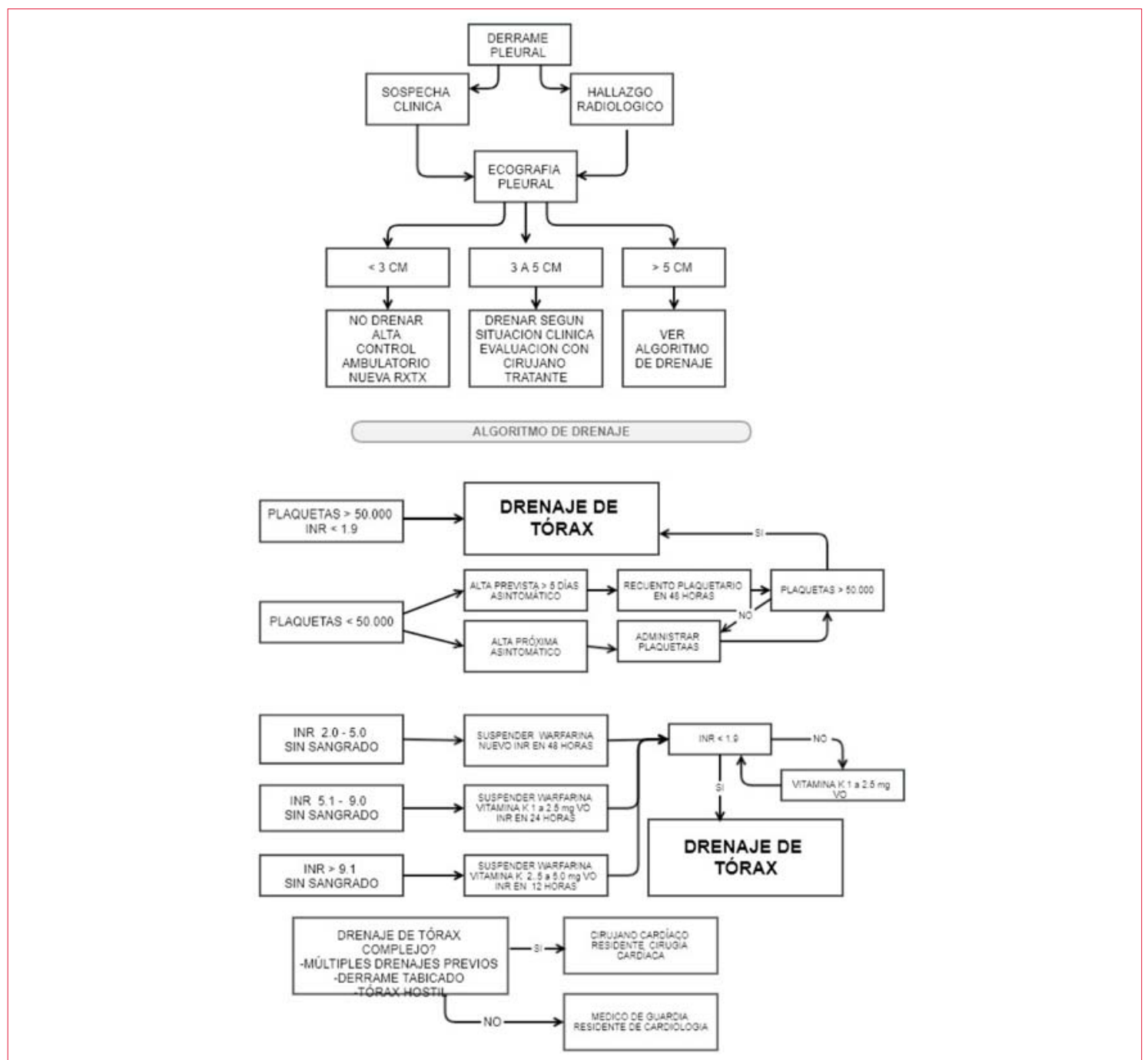

Figura 2. Algoritmo para drenaje del derrame pleural.

mo ketoprofeno $100 \mathrm{mg}$ IV cada 8-12 horas desde el primer día posoperatorio. Está contraindicado en insuficiencia renal o alergia al fármaco.

En derrames recidivantes o SPP se agrega colchicina, iniciando el tercer día posoperatorio con 1 mg cada 12 horas como dosis carga, seguido de 0,5 mg cada 12 horas $(0,25 \mathrm{mg}$ cada 12 horas si el peso corporal es $<70 \mathrm{~kg}$ ), manteniendo un mes. Debe suspenderse si aparece diarrea importante. El uso de corticoides o AAS no demostró beneficio, pero se intenta en casos recidivantes o refractarios bajo AINEs y colchicina.

En nuestra institución se utiliza un algoritmo de decisión para el abordaje de los derrames en pacientes con eventuales alteraciones de la hemostasis (figura 2).

\section{g. Atelectasia}

Es la pérdida parcial o total del volumen pulmonar. Puede ser por reabsorción del aire en una obstruc- ción del árbol respiratorio por secreciones, coágulos o por compresión extrínseca en un derrame o neumotórax parcial. Existen microatelectasias por falta de surfactante pulmonar en el SDRA o en la VM con $\mathrm{FiO}_{2} 100 \%$ que produce la reabsorción del nitrógeno alveolar y pérdida de la estructura. Los lóbulos inferiores son los más proclives a presentar atelectasia posoperatoria. Se ha demostrado que luego de 10 minutos de la inducción anestésica hasta $90 \%$ de pacientes presenta atelectasias en zonas pulmonares más dependientes persistiendo días, asociando hipoxemia e inflamación y favoreciendo la infección y otras complicaciones. Vinculado a la cirugía ocurre por parálisis frénica y suspensión de la VM durante el BPCP.

En el posoperatorio aparecen por la hipoventilación provocada por el dolor y la presencia de drenajes. El desplazamiento inadvertido del tubo orotraqueal al bronquio fuente derecho causa atelectasia del pulmón izquierdo. 


\begin{tabular}{|c|c|c|}
\hline Preoperatorias & Intraoperatorias & Posoperatorias \\
\hline FEVI severa & BPCP y/o clampeo prolongados ${ }^{\mathrm{a}}$ & Asincronía del ventilador \\
\hline Anemia & Hipoxemia & IAM perioperatorio \\
\hline $\begin{array}{l}\text { EPOC* } \\
\text { Asma }\end{array}$ & $\begin{array}{l}\text { Sangrado excesivo. } \\
\text { Transfusión masiva de hemoderivados }\end{array}$ & $\begin{array}{l}\text { Depresión de conciencia: ACV, } \\
\text { delirium, sedación }\end{array}$ \\
\hline Edad avanzada* & Hipotensión & SDRA \\
\hline Sexo femenino* & Hiperglicemia & Arritmias \\
\hline Tabaquismo* & Uso de BIAC** & Isquemia miocárdica \\
\hline Hipertensión pulmonar & Hipertensión pulmonar & Hipertensión pulmonar \\
\hline Fragilidad, desnutrición & & Disfunción diafragmática \\
\hline $\begin{array}{l}\text { Hipoalbuminemia } \\
\text { Diabetes mellitus* }\end{array}$ & Procedimientos combinados o complejos & Reoperación por complicaciones \\
\hline Cirugía de urgencia o emergencia & Requerimientos inotrópicos & Polineuromiopatía del enfermo crítico \\
\hline Insuficiencia renal & Shock cardiogénico & Lactacidemia elevada** \\
\hline \multicolumn{3}{|l|}{$\begin{array}{l}\text { Situación crítica preoperatoria } \\
\text { (inotrópicos, shock, etc.) }\end{array}$} \\
\hline $\begin{array}{l}\text { * Estos factores no han sido implicados e } \\
* * \text { Estos factores vinculados al procedim } \\
\text { FEVI: fracción de eyección del ventrícul } \\
\text { medad pulmonar obstructiva crónica, AC } \\
\text { traaórtico de contrapulso. }\end{array}$ & $\begin{array}{l}\text { a revisión reciente } \mathrm{e}^{(38)} \text {. } \\
\text { fueron los que mostraron mayor robustez } \\
\text { uierdo; BPCP: bypass cardiopulmonar; IAM } \\
\text { taque cerebrovascular; SDRA: sindrome de }\end{array}$ & $\begin{array}{l}\text { para determinar VMP( } 39) \text {. } \\
\text { I: infarto agudo de miocardio; EPOC: enfer } \\
\text { distrés respiratorio agudo; BIAC: balón in- }\end{array}$ \\
\hline
\end{tabular}

Radiológicamente se observan opacificaciones pulmonares con desplazamiento del mediastino, hilio o hemidiafragma hacia el área afectada y sobredistensión pulmonar compensatoria en la zona adyacente no atelectásica.

Para evitarlas, se sugiere utilizar en el perioperatorio, estrategias ventilatorias de reclutamiento alveolar y baja $\mathrm{FiO}_{2}$ como forma de evitar o revertir las atelectasias. Es fundamental la fisioterapia respiratoria precoz.

\section{h. Ventilación mecánica prolongada (VMP)}

Según la Society of Thoracic Surgeons (STS) se define como la ventilación mecánica mayor a 24 horas, tomadas desde el ingreso a cuidados intensivos.

En un estudio retrospectivo entre 2008 y 2012 en unidades de terapia intensiva de Andalucía, sobre 3.588 ingresos encontraron una incidencia de $11,6 \%$, asociada a $44,3 \%$ de mortalidad, fundamentalmente por disfunción orgánica múltiple y sepsis, comparado con $3,1 \%$ de mortalidad en pacientes extubados dentro de las 24 horas $^{(35)}$. Se asocia con edad avanzada, PCR posoperatorio y falla renal con terapia de remplazo, quintuplicando la mortalidad ${ }^{(36)}$.

Fue más frecuente luego de un procedimiento combinado (sustitución valvular y revascularización miocárdica), donde hay menor éxito en el destete y mayor mortalidad hospitalaria ${ }^{(37)}$.
Las causas son múltiples e interactúan, potenciando sus efectos deletéreos. Una lista no exhaustiva se incluye en la tabla 11.

Es un desafío desarrollar un score de riesgo válido basado en datos retrospectivos que prediga la probabilidad de VMP. La continua mejora de los procedimientos quirúrgicos y de cuidados críticos los vuelve obsoletos en pocos años. Los indicadores están más vinculados a complicaciones surgidas durante el proceso que a evaluaciones de potenciales patologías previas ${ }^{(36)}$. No se deben usar para determinar conductas sino para identificar y estratificar grupos de riesgo donde el control de la optimización ventilatoria y la completa preparación para la desvinculación debe ser extremada.

Fernández-Zamora y colaboradores ${ }^{(35)}$ encontraron una asociación progresiva entre ventilación prolongada y EuroSCORE con $4,5 \%$ en $<5,11,2 \%$ entre $5-7,27,2 \%$ entre $8-10$ y $32,2 \%$ si es $>10$.

La VMP estuvo significativamente asociada con historia de EPOC (17,1\% vs. $8,2 \%)$, tabaquismo $(21,4 \%$ vs $16,1 \%)$ y stroke ( $8,4 \%$ vs. $5,2 \%)$. No se encontró asociación con diabetes mellitus, hipertensión u obesidad.

La valoración preoperatoria adecuada con anticipación de semanas en las cirugías de coordinación es fundamental. Es necesario pesquisar y tratar aquellas variables importantes para llegar a la ciru- 


\begin{tabular}{|c|c|c|}
\hline Variable & Valor requerido & Acción \\
\hline Anemia & $\mathrm{Hb}$ en rango & $\begin{array}{l}\text { Protocolo optimización hematimétrica del } \\
\text { servicio mediante eritropoyetina y hierro } \\
\text { intravenoso previo despistaje de causas. }\end{array}$ \\
\hline FEVI con disminución severa & N/A & $\begin{array}{l}\text { Adecuación tratamiento con } \\
\text { betabloqueantes, IECA/ARA2, } \\
\text { espironolactona, sacubitril a dosis plenas. } \\
\text { Corregir hipervolemia. }\end{array}$ \\
\hline Hipoalbuminemia & Rango & Mejorar nutrición enteral. \\
\hline EFR alterado & N/A & $\begin{array}{l}\text { Fisioterapia, broncodilatadores de corta y } \\
\text { larga duración, corticoides, otros. }\end{array}$ \\
\hline \multicolumn{3}{|l|}{ ETT descartar HAP } \\
\hline Diabetes & $\mathrm{HbA} 1 \mathrm{C}<6 \%$ & $\begin{array}{l}\text { Consulta con endocrinólogo-diabetólogo. } \\
\text { Ajuste medicación. }\end{array}$ \\
\hline Fragilidad & $\begin{array}{l}\text { Consulta con geriatra, nutricionista y } \\
\text { fisioterapia }\end{array}$ & $\begin{array}{l}\text { Mejorar nutrición. } \\
\text { Ejercicios fisioterapia. }\end{array}$ \\
\hline Insuficiencia renal & Consulta con nefrólogo & Adecuar nutrición y tratamiento. \\
\hline
\end{tabular}

gía en la mejor situación. La paraclínica básica brinda datos importantes (tabla 12).

El desarrollo de complicaciones es más frecuente en caso de VMP.

La NAV es frecuente y aumenta la mortalidad. He y colaboradores ${ }^{(40)}$, en un metaanálisis de 11 estudios de NAV luego de la cirugía cardíaca, encontraron una tasa de 21 NAV cada 1.000 días de ventilación. La prevalencia alcanza 6,37\% global y asciende a $35,2 \%$ en pacientes con más de 48 horas de VM.

La disfunción de la deglución es una entidad desatendida en la evaluación del curso de la cirugía. Un estudio detectó su presencia mediante cinerradiografía con bario en $4 \%$ de una muestra de 900 cirugías cardíacas ${ }^{(41)}$. El $22 \%$ tenía reducción de la fase oral preparatoria, $67 \%$ deterioro del reflejo deglutorio, $48 \%$ cierre incompleto epiglótico y 56\% disminución de la peristalsis faríngea. Se documentó aspiración pulmonar en $90 \%$ de pacientes, con aspiración silente o ausencia de tos refleja en $22 \%$. No hubo diferencias entre los grupos en el tiempo de CEC, clampeo o complicaciones neurológicas. La presencia de disfunción se asoció con la edad (71 vs. 63 años; $p<0,0001$ ), bajo gasto cardíaco ( $15 \%$ vs. $6 \% ; \mathrm{p}=0,047)$, necesidad de balón intraaórtico de contrapulsación (BIAC) $(15 \%$ vs. $5 \%$; p<0,02), duración de la intubación $(5,2 \pm 1,7$ vs. $2,1 \pm 0,2$ días; $\mathrm{p}=0,0006)$, uso de ecocardiograma transesofágico (ETE) perioperatorio (68\% vs. $48 \%$; $\mathrm{p}=0,001$, hospitalización posoperatoria $(33,4 \pm 4,4$ vs. $12,3 \pm 0,4$ días; $\mathrm{p}=0,001)$. Este grupo requirió más traqueostomías ( $18 \%$ vs. $2 \%$; p < 0,001 y desarrolló más neumonía (41\% vs. $8 \%$; p <0,0001).

La injuria laríngea aguda (ulceración mucosa o tejido de granulación en laringe) estuvo presente en 57\% de las laringoscopías realizadas dentro de las 36 horas de extubación. Los pacientes tuvieron peor percepción de adecuada ventilación y disfonía, que se mantuvieron hasta diez semanas luego de la extubación. Las sondas orotraqueales mayores a 7,0, diabetes y elevado IMC predispusieron a las lesiones ${ }^{(42)}$.

Cuando son referidos a centros terciarios para la evaluación de secuelas deglutorias o trastornos de la voz, el problema es mayor. Miles y colaboradores $^{(43)}$, analizando 106 pacientes, encontraron $39 \%$ de aspiración silente, $65 \%$ de edema laríngeo y $61 \%$ de parálisis de cuerda vocal. La incidencia de neumonía fue de $36 \%$ y la de stroke posoperatorio $14 \%$. Las alteraciones en la motilidad de las cuerdas vocales tuvieron una asociación estadísticamente significativa con el tiempo de VM y la duración de la traqueostomía.

El mejor tratamiento es la prevención. Evaluar y corregir durante las semanas previas a la cirugía los factores ya analizados. Alcanzar un adecuado estado nutricional, corregir la anemia, realizar fisioterapia respiratoria y muscular, así como el cese del tabaquismo es mandatorio.

La extubación precoz, entre las 6 y 12 horas del ingreso a terapia intensiva, es factible a través de protocolos específicos del servicio, con la interven- 
ción del médico, el licenciado en fisiatría y el personal de enfermería.

Es importante obtener un nivel adecuado de analgosedación, evitando la sobredosificación que disminuya el estado de alerta o la fuerza muscular.

Actualmente se aconsejan protocolos que incluyan fentanilo o paracetamol parenteral para analgesia junto a dexmedetomidina en sedación consciente. La morfina produce mayores alteraciones hemodinámicas y respiratorias, asociando más delirium posoperatorio. Las benzodiazepinas parenterales producen disminución del nivel de conciencia, resolución muscular y depresión del centro respiratorio.

Si bien usualmente se trata de ventilaciones cortas, es importante el adecuado ajuste del ventilador para evitar disincronías y daño pulmonar. El ajuste inicial ${ }^{(30)}$ al ingreso a terapia intensiva incluye:

Modo asistido controlado por volumen o presión (A/C VCV o PCV).

- $\mathrm{V}_{\mathrm{T}} 6 \mathrm{ml} / \mathrm{kg}$ del peso calculado.

- Frecuencia respiratoria (FR) 12-16 por minuto.

- $\mathrm{FiO}_{2}$ 1,0 para cálculo inicial de shunt.

- PEEP $5 \mathrm{~cm} \mathrm{H}_{2} \mathrm{O}$.

- Presión plateau o presión pico $\leq 30 \mathrm{~cm} \mathrm{H}_{2} \mathrm{O}$.

- $\Delta \mathrm{P} \leq 15 \mathrm{~cm} \mathrm{H}_{2} \mathrm{O}$.

Debe monitorizarse estrechamente todo el proceso de VM para identificar en forma rápida la presencia de asincronía paciente-ventilador ${ }^{(19,44)} \mathrm{o}$ indicadores de potencial VILI ${ }^{(45)}$, o ambos.

La adecuada y pronta corrección disminuye la prolongación del tiempo de ventilación, así como el daño pulmonar secundario.

Las estrategias de desvinculación son varias y deben planificarse en forma paulatina.

Es recomendable realizar una PVE diaria si cumple criterios de destete.

La traqueostomía (TQ) es un procedimiento habitual en pacientes críticos que requieren VMP. Mejora el confort, el cuidado oral y la comunicación. Reduce la analgosedación, la incidencia de NAV, favorece la desvinculación y es costo-efectiva. La indicación de TQ precoz (antes del 14 día) estuvo asociada a menor tiempo de VM (31,3 vs. 39,4 días; $\mathrm{p}=0,034)$ y estadía, sin cambios en la mortalidad ${ }^{(46)}$. La baja sensibilidad de los scores predictivos de VMP, así como su desvinculación, requieren una indicación basada en la clínica y el criterio temporal.

Debe tenerse en cuenta la proximidad de la esternotomía para evitar infección, si bien en el estudio esta posibilidad fue baja. Cada vez más se realiza TQ percutánea en servicios con experiencia y en pacientes adecuadamente seleccionados.

\section{Conclusiones}

En los últimos tiempos la cirugía cardíaca se ha tornado más compleja, tanto por las características de los pacientes como por las de los procedimientos realizados. Este fenómeno se ha acompañado de la modernización en la técnica quirúrgica y en los cuidados posoperatorios. Es así que el ámbito de las complicaciones respiratorias adquiere características particulares y específicas.

Sergio Cáceres, https://orcid.org/0000-0002-3577-5936

Olivier Bertaux, https://orcid.org/0000-0002-5777-3552

Ignacio Porras, https://orcid.org/0000-0002-6445-3805

Este artículo fue aceptado para su publicación por: Editor invitado Dr. Oscar Bazzino

\section{Bibliografía}

1. Riesgo M. Cuidados perioperatorios en cirugía cardiovascular. Rev Esp Cardiol. 2001; 54(8):1018. doi:10.1016/S0300-8932(01)76443-3

2. Engelman D, Ben Ali W, Williams J, Perrault L, Reddy V, Arora R, et al. Guidelines for perioperative care in cardiac surgery: enhanced recovery after surgery society recommendations. JAMA Surg. 2019; 154(8):755-66. doi: 10.1001/jamasurg.2019. 1153

3. Jammer I, Wickboldt N, Sander M, Smith A, Schultz M, Pelosi P, et al. Standards for definitions and use of outcome measures for clinical effectiveness research in perioperative medicine: European Perioperative Clinical Outcome (EPCO) definitions: a statement from the ESA-ESICM joint taskforce on perioperative outcome measures. Eur J Anaesthesiol. 2015; 32(2):88-105. doi: 10.1097/EJA.0000000000000118

4. Miskovic A, Lumb A. Postoperative pulmonary complications. Br J Anaesth. 2017; 118(3):317-34. doi: 10.1093/bja/aex002

5. Puis L, Milojevic M, Boer C, De Somer F, Gudbjartsson T, van den Goor J, et al. 2019 EACTS/EACTA/EBCP guidelines on cardiopulmonary bypass in adult cardiac surgery. Interact Cardiovasc Thorac Surg. 2020; 30(2):161-202. doi: 10.1093/icvts/ivz251

6. Ranieri V, Rubenfeld G, Thompson B, Ferguson N, Caldwell E, Fan E, et al. Acute respiratory distress syndrome: the Berlin definition. JAMA. 2012; 307(23):2526-33. doi: 10.1001/jama.2012.5669

7. Kor D, Lingineni R, Gajic O, Park P, Blum J, Hou $\mathbf{P}$, et al. Predicting risk of postoperative lung injury in high-risk surgical patients: a multicenter cohort study. Anesthesiology. 2014; 120(5):1168-81. doi: 10.1097/ALN.0000000000000216 
8. Mathis M, Duggal N, Likosky D, Haft J, Douville $\mathbf{N}$, Vaughn M, et al. Intraoperative mechanical ventilation and postoperative pulmonary complications after cardiac surgery. Anesthesiology. 2019; 131(5):1046-62. doi: 10.1097/ALN.0000000000002909

9. Brower R, Matthay M, Morris A, Schoenfeld D, Thompson B, Wheeler A. Ventilation with lower tidal volumes as compared with traditional tidal volumes for acute lung injury and the acute respiratory distress syndrome. N Engl J Med. 2000; 342(18):1301-8. doi 10.1056/NEJM200005043421801

10. Griffiths M, McAuley D, Perkins G, Barrett N, Blackwood B, Boyle A, et al. Guidelines on the management of acute respiratory distress syndrome. BMJ Open Respir Res. 2019; 6(1):e000420. doi 10.1136/bmjresp-2019-000420

11. Cui Y, Cao R, Wang Y, Li G. Lung recruitment maneuvers for ards patients: a systematic review and meta-analysis. Respiration. 2020; 99(3):264-76. doi: $10.1159 / 000501045$

12. Papazian L, Forel J, Gacouin A, Penot-Ragon C, Perrin G, Loundou A, et al. Neuromuscular blockers in early acute respiratory distress syndrome. N Engl J Med. 2010; 363(12):1107-16. doi: 10.1056/NEJMoa1005372

13. Scholten E, Beitler J, Prisk G, Malhotra A Treatment of ARDS with prone positioning. Chest. 2017; 151(1):215-24. doi: 10.1016/j.chest.2016.06. 032

14. Saha S, Jebran A, Leistner M, Kutschka I, Niehaus H. Turning things around: the role of prone positioning in the management of acute respiratory failure after cardiac surgery. J Cardiothorac Vasc Anesth. 2020; 34(6):1434-8. doi: 10.1053/j. jvca.2019.10.055

15. von Wardenburg C, Wenzl M, Dell'Aquila A, Junger A, Fischlein T, Santarpino G. Prone positioning in cardiac surgery: for many, but not for everyone. Semin Thorac Cardiovasc Surg. 2016; 28(2):281-7. doi: 10.1053/j.semtcvs.2016.04.008

16. Stepahn F, Perrier J, Moore A, Serfati C, Imbert A, Amaru P. Effects of prone position in obese patients with ards after cardiothoracic surgery. Am J Resp Crit Care Med. 2018; 197:A5068.Disponible en: https://www.atsjournals.org/doi/abs/ 10.1164/ajrccm-conference.2018.197.1_MeetingAbstracts.A5068. [Consulta: 15 julio 2020].

17. Setten M, Plotnikow G, Accoce M. Prone position in patients with acute respiratory distress syndrome. Rev Bras Ter Intensiva. 2016; 28(4):452-62. doi: 10.5935/0103-507X.20160066

18. Villar J, Ferrando C, Martínez D, Ambrós A, Muñoz T, Soler J, et al. Dexamethasone treatment for the acute respiratory distress syndrome: a multicentre, randomised controlled trial. Lancet Respir
Med. 2020; 8(3):267-76. doi: 10.1016/S22132600(19)30417-5

19. Bruni A, Garofalo E, Pelaia C, Messina A, Cammarota G, Murabito P, et al. Patient-ventilator asynchrony in adult critically ill patients. Minerva Anestesiol. 2019; 85(6):676-88. doi: 10.23736/S03759393.19.13436-0

20. Moury P, Cuisinier A, Durand M, Bosson J, Chavanon O, Payen J, et al. Diaphragm thickening in cardiac surgery: a perioperative prospective ultrasound study. Ann Intensive Care. 2019; 9(1):50. doi: 10.1186/s13613-019-0521-z

21. Cavayas Y, Eljaiek R, Rodrigue É, Lamarche Y, Girard M, Wang H, et al. Preoperative diaphragm function is associated with postoperative pulmonary complications after cardiac surgery. Crit Care Med. 2019; 47(12):e966-74. doi: 10.1097/CCM.0000000000004027

22. Torres A, Niederman M, Chastre J, Ewig S, Fernandez-Vandellos $P$, Hanberger $\mathrm{H}$, et al. International ERS/ESICM/ESCMID/ALAT guidelines for the management of hospital-acquired pneumonia and ventilator-associated pneumonia: guidelines for the management of hospital-acquired pneumonia (HAP)/ventilator-associated pneumonia (VAP) of the European Respiratory Society (ERS), European Society of Intensive Care Medicine (ESICM), European Society of Clinical Microbiology and Infectious Diseases (ESCMID) and Asociación Latinoamericana del Tórax (ALAT). Eur Respir J. 2017; 50(3):1700582. doi: 10.1183/13993003.00582-2017

23. Díaz E, Martín-Loeches I, Vallés J. Neumonía nosocomial. Enferm Infecc Microbiol Clin. 2013; 31(10):692-8. doi:10.1016/j.eimc.2013.04.014

24. Ailawadi G, Chang H, O'Gara P, O'Sullivan K, Woo Y, DeRose J, et al. Pneumonia after cardiac surgery: experience of the National Institutes of Health/Canadian Institutes of Health Research Cardiothoracic Surgical Trials Network. J Thorac Cardiovasc Surg. 2017; 153(6):1384-91.e3. doi: 10.1016/j.jtcvs.2016.12.055

25. Ferrer M, Torres A. Epidemiology of ICU-acquired pneumonia. Curr Opin Crit Care. 2018; 24(5):325-31. doi: 10.1097/MCC.0000000000000536

26. Fernando S, Tran A, Cheng W, Klompas M, Kyeremanteng K, Mehta S, et al. Diagnosis of ventilator-associated pneumonia in critically ill adult patients-a systematic review and meta-analysis. Intensive Care Med. 2020; 46(6):1170-9. doi: $10.1007 / \mathrm{s} 00134-020-06036-\mathrm{z}$

27. Kalil A, Metersky M, Klompas M, Muscedere J, Sweeney D, Palmer L, et al. Management of adults with hospital-acquired and ventilator-associated pneumonia: 2016 clinical practice guidelines by the Infectious Diseases Society of America and the 
American Thoracic Society. Clin Infect Dis. 2016; 63(5):e61-111. doi: 10.1093/cid/ciw353

28. Coelho L, Rabello L, Salluh J, Martin-Loeches I, Rodriguez A, Nseir S, et al. C-reactive protein and procalcitonin profile in ventilator-associated lower respiratory infections. J Crit Care. 2018; 48:385-9. doi: 10.1016/j.jcrc.2018.09.036

29. Berton D, Kalil A, Teixeira P. Quantitative versus qualitative cultures of respiratory secretions for clinical outcomes in patients with ventilator-associated pneumonia. Cochrane Database Syst Rev. 2014; (10) CD006482. doi: 10.1002/14651858.CD006482.pub4

30. Álvarez-Lerma F, Torres A, Rodríguez De Castro F. Recomendaciones para el diagnóstico de la neumonía asociada a ventilación mecánica. Enferm Infecc Microbiol Clin. 2001; 19(10):479-87. doi: $10.1016 / \mathrm{s} 0213-005 \mathrm{x}(01) 72706-1$

31. Arthur L, Kizor R, Selim A, van Driel M, Seoane L. Antibiotics for ventilator-associated pneumonia. Cochrane Database Syst Rev. 2016; 10(10):CD004267. doi: 10.1002/14651858.CD004267. pub4

32. Papazian L, Klompas M, Luyt C. Ventilator-associated pneumonia in adults: a narrative review. Intensive Care Med. 2020; 46(5):888-906. doi 10.1007/s00134-020-05980-0

33. Liu D, Zhang J, Liu H, Zhu Y, Qu J. Intravenous combined with aerosolised polymyxin versus intravenous polymyxin alone in the treatment of pneumonia caused by multidrug-resistant pathogens: a systematic review and meta-analysis. Int $\mathrm{J}$ Antimicrob Agents. 2015; 46(6):603-9. doi: 10.1016/j.ijantimicag.2015.09.011

34. Oz B, Iyem H, Akay H, Yildirim V, Karabacak K, Bolcal C, et al. Preservation of pleural integrity during coronary artery bypass surgery affects respiratory functions and postoperative pain: a prospective study. Can Respir J. 2006; 13(3):145-9. doi: 10.1155/ 2006/682575

35. Fernández-Zamora M, Gordillo-Brenes A, Banderas-Bravo E, Arboleda-Sánchez J, Hinojosa-Pérez R, Aguilar-Alonso E, et al. Prolonged mechanical ventilation as a predictor of mortality after cardiac surgery. Respir Care. 2018; 63(5):550-7. doi: 10.4187/respcare.04915

36. Suarez-Pierre A, Fraser C, Zhou X, Crawford T, Lui C, Metkus T, et al. Predictors of operative mortality among cardiac surgery patients with prolonged ventilation. J Card Surg. 2019; 34(9):759-66. doi: $10.1111 /$ jocs. 14118

37. Vagheggini G, Vlad E, Mazzoleni S, Bortolotti U, Guarracino F, Ambrosino N. Outcomes for difficult-to-wean subjects after cardiac surgery. Respir Care. 2015; 60(1):56-62. doi: 10.4187/respcare.03315

38. Siddiqui M, Paras I, Jalal A. Risk factors of prolonged mechanical ventilation following open heart surgery: what has changed over the last decade? Cardiovasc Diagn Ther. 2012; 2(3):192-9. doi: 10.3978/j.issn.2223-3652.2012.06.05

39. Zante B, Erdoes G. Risk of prolonged mechanical ventilation after cardiac surgery: predicting the unpredictable? J Cardiothorac Vasc Anesth. 2019; 33(10):2717-8. doi: 10.1053/j.jvca.2019.04.008

40. He S, Chen B, Li W, Yan J, Chen L, Wang X, et al. Ventilator-associated pneumonia after cardiac surgery: a meta-analysis and systematic review. J Thorac Cardiovasc Surg. 2014; 148(6):3148-55.e1-5. doi: $10.1016 / j$.jtcvs.2014.07.107

41. Hogue C, Lappas G, Creswell L, Ferguson T, Sample M, Pugh D, et al. Swallowing dysfunction after cardiac operations. Associated adverse outcomes and risk factors including intraoperative transesophageal echocardiography. J Thorac Cardiovasc Surg. 1995; 110(2):517-22. doi: 10.1016/S0022-5223 (95) 70249-0

42. Shinn J, Kimura K, Campbell B, Sun Lowery A, Wootten C, Garrett C, et al. Incidence and outcomes of acute laryngeal injury after prolonged mechanical ventilation. Crit Care Med. 2019; 47(12): 1699-706. doi: 10.1097/CCM.0000000000004015

43. Miles A, McLellan N, Machan R, Vokes D, Hunting A, McFarlane M, et al. Dysphagia and laryngeal pathology in post-surgical cardiothoracic patients. J Crit Care. 2018; 45:121-7. doi: 10.1016/ j.jcrc.2018.01.027

44. Thille A, Pham T. Asynchronies patient-ventilateur. Méd Intensive Réa. 2018; 27(1):67-73. doi:10.3166/rea-2018-0013

45. Beitler J, Malhotra A, Thompson B. Ventilator-induced Lung Injury. Clin Chest Med. 2016; 37(4):633-46. doi: 10.1016/j.ccm.2016.07.004

46. Affronti A, Casali F, Eusebi P, Todisco C, Volpi F, Beato V, et al. Early versus late tracheostomy in cardiac surgical patients: a 12-year single center experience. J Cardiothorac Vasc Anesth. 2019; 33(1): 82-90. doi: 10.1053/j.jvca.2018.05.041 